\title{
Review: nedocromil sodium decreases airflow reduction and recovery time in exercise induced bronchoconstriction
}

Spooner CH, Saunders LD, Rowe BH. Nedocromil sodium for preventing exercise-induced bronchoconstriction. Cochrane

Database Syst Rev 2002(2):CD:001183 (latest version 20 Sep 2001).

\section{QUESTION: In patients with exercise induced bronchoconstriction (EIB), is nedocromil sodium effective for reducing the severity and duration of symptoms?}

\section{Data sources}

Studies were identified by searching the Cochrane Airways Group trial register; the Cochrane Controlled Trials Register; Current Contents; and bibliographies of relevant studies, review articles, and textbooks. The manufacturer of nedocromil sodium (Rhône-Poulenc Rorer) and study authors were contacted.

\section{Study selection}

2 reviewers independently selected studies if they were randomised, double blind, controlled trials; any dose of inhaled nedocromil sodium was compared with placebo before exercise; and patients had a history of EIB or showed evidence of EIB (reduction of $\mathrm{FEV}_{1}$ or peak expiratory flow rate $[\mathrm{PEFR}] \geq 10 \%$ ) in an exercise challenge before study entry. Studies using delivery by nasal spray were excluded.

\section{Data extraction}

2 reviewers independently assessed the quality of studies and extracted data on patients, interventions, and outcomes (mean maximum percentage reduction in $\mathrm{FEV}_{1}$ or PEFR, mean percentage reduction in $\mathrm{FEV}_{1}$ across time, and protection index).

\section{Main results}

21 studies (300 patients) met the selection criteria. 10 studies were in children, 6 studies were in adults, and 5 studies included both adults and children. The sample sizes ranged from 8 to 24 patients (mean 14 patients). Nedocromil sodium doses ranged from 1 to $8 \mathrm{mg}$ and were given by a metered dose inhaler ( 5 studies used a spacer device) 15 to 60 minutes before exercise. Nedocromil sodium led to attenuation of the mean maximum reduction of $\mathrm{FEV}_{1}$ after exercise (17 studies, $\mathrm{n}=240$ ) (table). Studies reporting the mean maximum reduction of PEFR were heterogeneous; when studies were divided according to severity of symptoms, the heterogeneity disappeared. Nedocromil sodium attenuated the mean maximum percentage reduction in PEFR in patients with more severe EIB to a greater degree than in patients with mild EIB (table). The protection index against a reduction in $\mathrm{FEV}_{1}$ relative to placebo was $51 \%$ (95\% CI 46\% to 55\%). For reduction in PEFR relative to placebo, the protection index was $49 \%$ (CI $40 \%$ to $58 \%$ ). The group difference in mean change in $\mathrm{FEV}_{1}$ favouring nedocromil remained across 7 time points up to 30 minutes after exercise; the return to normal lung function occurred within 10 minutes after exercise for nedocromil sodium compared with 30 minutes for placebo.

\section{Conclusion}

In patients with exercise induced bronchoconstriction, nedocromil sodium decreases the reduction in airflow and time to recovery.
Source of funding: Institute of Health Economics, Alberta, Canada.

For correspondence: Mrs C Spooner, University of Alberta,

Edmonton, Alberta, Canada.

cspooner@ualberta.ca

Nedocromil sodium (Ned) v placebo for exercise induced bronchoconstriction*

\begin{tabular}{|c|c|c|c|}
\hline \multirow[b]{2}{*}{ Outcomes } & \multicolumn{2}{|c|}{ Weighted means } & \multirow[b]{2}{*}{ Weighted mean difference (95\% Cl) } \\
\hline & Ned & Placebo & \\
\hline Maximum reduction in $\mathrm{FEV}_{1}$ & $14.5 \%$ & $30.1 \%$ & $15.6 \%(13.2$ to 18.1$)$ \\
\hline Maximum reduction in PEFR & $14.3 \%$ & $29.3 \%$ & $15.0 \%(8.3$ to 21.6$)$ \\
\hline
\end{tabular}

${ }^{*} \mathrm{PEFR}=$ peak expiratory flow rate. $\mathrm{Cl}$ defined in glossary. Weighted mean differences were calculated using a fixed effects model.

\section{COMMENTARY}

EIB is an important problem with a complex cause. The short acting, inhaled anti-inflammatory drug nedocromil sodium has been evaluated as prophylaxis for this condition in several small studies; however, its effect on EIB is still controversial. The meta-analysis of 20 randomised controlled trials by Spooner et al clearly shows that 4 $\mathrm{mg}$ of inhaled nedocromil sodium taken before exercise is effective in EIB and decreases the exercise induced reduction in airflow by $50 \%$ and the time to recover to normal lung function by more than $50 \%$. Patients with the most severe EIB symptoms achieved the greatest benefit.

This study is a well performed meta-analysis with rigorous methodology. The limitations of the review are clearly described, and 2 are of particular interest to clinicians. Firstly, all studies were done in the exercise laboratory under controlled conditions of temperature, humidity, exercise type, and presumably low aero-allergen exposure. As the cause of EIB is complex and these factors may be important when the patient is exercising in different seasons (eg, colder and less humid conditions in winter, more aero-allergens in spring) or playing different sports (explosive $v$ endurance sports), the effect of nedocromil sodium under real exercise conditions may not match the laboratory findings. Secondly, symptoms were not reported as outcomes in any of the studies. However, the magnitude of the protection against airflow reduction and the reduction in recovery time indicate clinically meaningful benefits.

Physical activity and sports are potential contributors to quality of life. The meta-analysis by Spooner et al summarises the relevant evidence showing that nedocromil sodium is effective as a prophylactic agent. Direct comparisons with pre-exercise $\beta$ agonists and disodium chromoglycate are needed to clarify therapeutic rankings, as are combination studies to assist patients with incomplete symptomatic benefit from a single agent, such as nedocromil.

Dion Grosser, MD Brian Smith, MBBS Queen Elizabeth Hospital Woodville, South Australia, Australia 